\title{
Phosphate feeding to permit growth while maintaining secondary product synthesis
}

\author{
Gregory F. Payne* and Henry Y. Wang \\ Department of Chemical Engineering, The University of Michigan, Ann Arbor, MI 48109, USA
}

Summary. Maintaining high metabolic activities for extended periods by feeding small amounts of the growth limiting nutrient was examined for the production of cycloheximide by Streptomyces griseus. Batch studies indicated that increased initial phosphate levels led to increased cell concentrations, stimulated glucose utilization, and over a limited range $\left(<0.6 \mathrm{~g} / 1 \quad \mathrm{KH}_{2} \mathrm{PO}_{4}\right)$ did not adversely affect cycloheximide production rates. Semi-continuous phosphate feeding was observed to permit limited cell growth, and to enhance metabolic activities (i. e. glucose utilization). The effect of semi-continuous phosphate feeding on antibiotic production depended on the feed rate, with high feed rates suppressing production.

\section{Introduction}

It is currently believed that secondary metabolism is triggered when levels of an essential nutrient are insufficient to support rapid growth (Martin and Demain 1980). Often this growth limiting nutrient is phosphate, and the effects of phosphate on secondary metabolism are reviewed by Martin (1977) and Weinberg (1978). Although limiting growth may be essential for secondary metabolite production, the complete suppression of growth may be unfavorable. Pirt and Righelato (1967) reported that the productivity of Penicillium chrysogenum for penicillin production decayed over time when the growth rate was maintained below about $0.014 \mathrm{~h}^{-1}$.

\footnotetext{
* Present address: Department of Chemical Engineering, University of Maryland Baltimore County Campus, Baltimore, MD 21228, USA

Offprint requests to: G. F. Payne
}

The goal of this work was to examine the effects of phosphate feeding on growth and cycloheximide production by Streptomyces griseus. Initial work by Abou-Zeid (1972) suggested the importance of phosphate on cell growth and cycloheximide production. Later work demonstrated that net cycloheximide synthesis required the presence of glucose (Kominek 1975a; Payne 1984). Also this fermentation was observed to be feedback regulated (Kominek 1975a) and most recent research has concentrated on the use of online product removal to circumvent this regulation (Kominek 1975b; Wang et al. 1981). Through the use of on-line product removal and computer controlled glucose feeding, it was observed that cycloheximide production could be increased by a factor of two to three (Payne 1984). However, over extended periods, the cycloheximide productivity decreased, and this reduced productivity appeared to correlate with a diminished metabolic activity of the cells (i. e. reduced rates of glucose and oxygen consumption, and carbon dioxide evolution). Controlled feeding of the growth limiting nutrient may prevent the decay in cycloheximide production and results from this work indicate that for this system, phosphate limits cell growth, and slow phosphate feeding can be used to maintain high metabolic activities without disrupting secondary metabolite synthesis.

\section{Materials and methods}

Microorganism and cultivation

Spores of Streptomyces griseus UC-2132 were used to inoculate seed medium as described by Kominek (1975a). Seed cultures were incubated in shake flasks for 2 to 3 days at $25^{\circ} \mathrm{C}$ on rotary shakers (300 RPM). 
The standard fermentation medium contained cerelose, $60 \mathrm{~g}$; defatted soybean flour, $15 \mathrm{~g}$; yeast, $2.5 \mathrm{~g}$; $\left(\mathrm{NH}_{4}\right)_{2} \mathrm{SO}_{4}$, $5 \mathrm{~g} ; \mathrm{CaCo}_{3}, 8 \mathrm{~g} ; \mathrm{NaCl}, 4 \mathrm{~g}$; and $\mathrm{KH}_{2} \mathrm{PO}_{4}, 0.2 \mathrm{~g}$ in one liter of water. Adjustments made to this medium for specific experiments are described in the text. Experiments were begun by inoculating the fermentation medium with $10 \%$ seed culture.

For shake flask studies, cells were incubated in $250 \mathrm{ml} \mathrm{Er}$ lenmeyer flasks ( $50 \mathrm{ml}$ liquid volume) at $25^{\circ} \mathrm{C}$ with aeration and agitation provided by rotary shaking (300 RPM). A 3-liter (liquid volume) fermentor (New Brunswick Scientific Co.) was also employed in this work. The fermentation was run at constant temperature $\left(25^{\circ} \mathrm{C}\right)$, and sterile air was supplied at a rate of $21 / \mathrm{min}$. The impeller speed was maintained at $500 \mathrm{RPM}$. At the conclusion of each experiment, samples were aseptically plated onto nutrient agar to ensure that contamination had not occurred.

To employ the neutral polymeric sorbent, XAD-4 (Rohm and Haas), the sorbent was first soaked in methanol for $24 \mathrm{~h}$, washed with several volumes of water and the moist sorbent was autoclaved. For the experiments described in Fig. 3, the broth was harvested from the fermentor on the fourth day, centrifuged for $20 \mathrm{~min}$ at $2500 \mathrm{RPM}$ and the supernatant contacted with the sterile resin for approximately $2 \mathrm{~h}$. After contacting, the supernatant was filtered to remove the resin and the supernatant and cell fractions were combined. $50 \mathrm{ml}$ of this broth was then transferred to a sterile flask containing glucose.

\section{Assay procedures}

To determine the sugar and antibiotic concentrations, cells were removed from the culture broth by centrifugation ( 2500 RPM for $20 \mathrm{~min}$ ). The antibiotic was first extracted from the supernatant using $5 \mathrm{ml}$ butyl acetate per $\mathrm{ml}$ supernatant, and an appropriate amount of the organic was dried. The cycloheximide concentration was then determined by the resorcinol colorimetric assay proposed by Takeshita et al. (1962).

Reducing sugars were assayed by the Somogyi (1952) method. Because glucose was the major sugar in the fermentation medium, the results were calibrated to equivalent glucose concentrations, and all data was reported as such.

It was necessary to remove the insoluble calcium carbonate for the determination of cell dry weight. To do this $25 \mathrm{ml}$ of the culture broth was mixed with an equivalent volume of $1 \mathrm{~N}$ hydrochloric acid. After centrifuging (2500 RPM for $20 \mathrm{~min}$ ), the pellet was washed twice with distilled water, and transferred to preweighed dishes. These samples were then dried at $70^{\circ} \mathrm{C}$ for 4 days.

\section{Results and discussion}

\section{Effects of initial phosphate}

Table 1 shows that the addition of $\mathrm{KH}_{2} \mathrm{PO}_{4}$ to this complex fermentation medium permitted increased cell growth. These data suggest that phosphorous is the growth limiting nutrient in this medium.

Figure 1 shows the effect of varying initial inorganic phosphate levels on the fermentation dynamics. Increases in the initial phosphate level stimulated glucose consumption, while above
Table 1. Effect of initial phosphate on cell growth. Cultures were harvested 3.7 days after inoculation

\begin{tabular}{ll}
$\begin{array}{l}\text { Initial } \mathrm{KH}_{2} \mathrm{PO}_{4} \\
(\mathrm{~g} / \mathrm{l})\end{array}$ & $\begin{array}{l}\text { Final dry cell } \\
\text { concentration } \\
(\mathrm{g} / \mathrm{l})\end{array}$ \\
\hline 0 & 10.3 \\
0.2 & 10.7 \\
0.4 & 12.8 \\
0.6 & 14.0 \\
\hline
\end{tabular}

$0.1 \mathrm{~g} / 1 \mathrm{KH}_{2} \mathrm{PO}_{4}$, increased phosphate levels did not adversely affect cycloheximide synthesis. Below $0.1 \mathrm{~m} / 1, \mathrm{KH}_{2} \mathrm{PO}_{4}$ actually stimulated cycloheximide production. Figure 1 also shows that the maximum cycloheximide concentration decreased with increased initial $\mathrm{KH}_{2} \mathrm{PO}_{4}$. Since cycloheximide synthesis ceases when glucose is depleted from the medium (see Fig. 1), the reduction in titers with increased $\mathrm{KH}_{2} \mathrm{PO}_{4}$ appears to result from the stimulation of glucose uptake and the early depletion of this sugar by cells cultured at high phosphate levels.

These observations suggest phosphate to be the limiting nutrient in this medium and are similar to results from fermentations for the production of chlortetracycline (Doskocil et al. 1959), streptomycin (Shirato and Nagatsu 1965), vancomycin (Mertz and Doolin 1973), alkaloids (Rao and Gupta 1975), candicidin (Liu et al. 1975; Martin and Demain 1976; Liras et al. 1977) and thienamycin (Lilley et al. 1981). Although phosphate levels were not measured in the present studies, others have observed that production commences (Doskocil et al. 1959; Liras et al. 1977), or production is highest (Lilley et al. 1981) after phosphate is depleted from the medium.

\section{Effects of phosphate feeding}

To examine the effect of phosphate additions on the fermentation dynamics, 3-liter fermentation runs were conducted. Figure $2 \mathrm{~A}$ shows that in the control (no phosphate added), slow, linear growth was observed after the first day. Compared to this control, Fig. 2B shows that daily phosphate additions at a rate of $0.2 \mathrm{~g} \mathrm{KH}_{2} \mathrm{PO}_{4} / 1$-day enhanced growth (1.1 vs $0.6 \mathrm{~g} / 1$-day), glucose consumption (11.9 vs $8.8 \mathrm{~g} / 1$-day) but suppressed cycloheximide productivities (53 vs $206 \mathrm{mg} / \mathrm{l}$-day). It should be noted that the constant phosphate addition rate supported linear (not exponential) growth. This data suggests that slow phosphate 

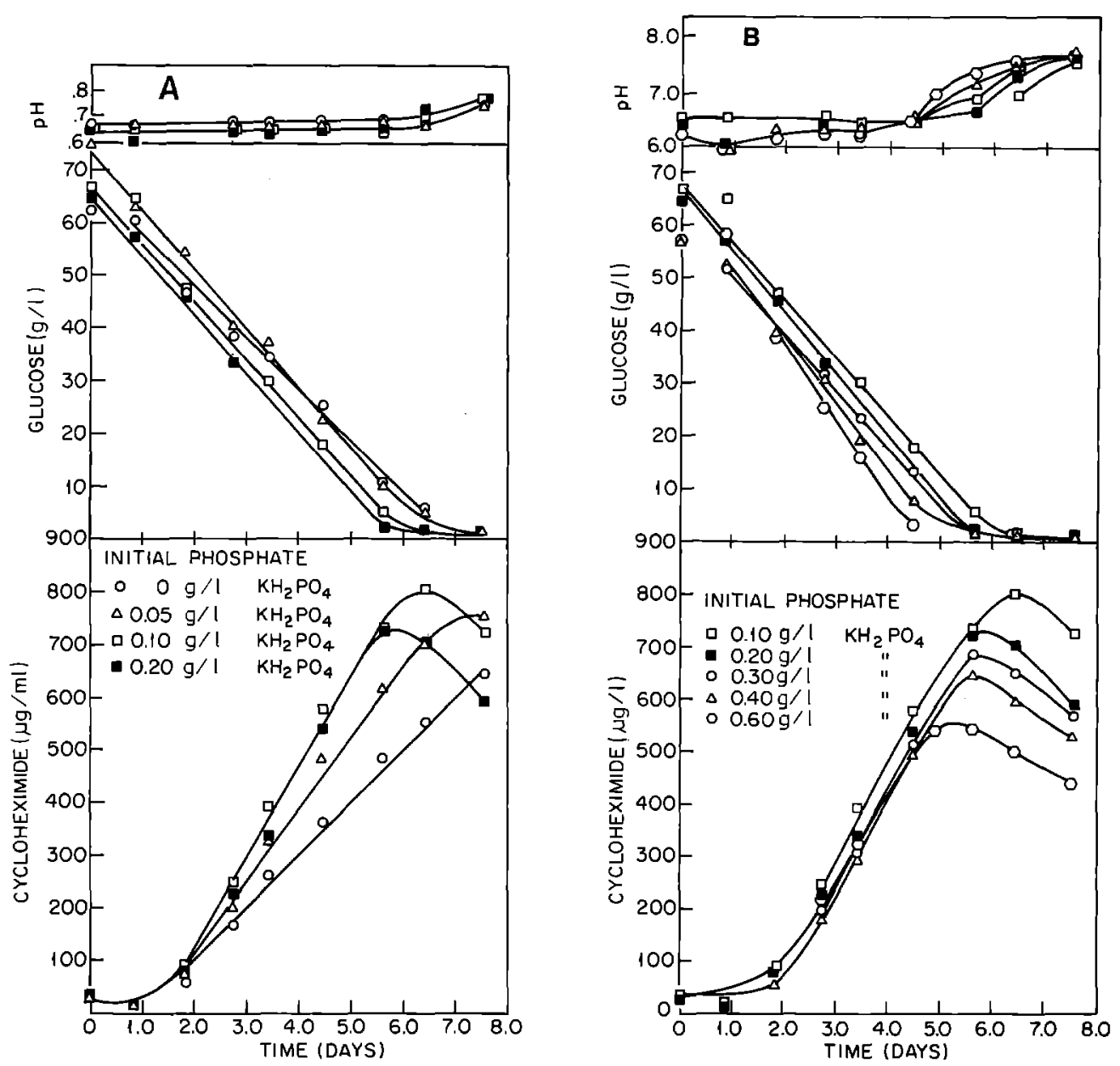

Fig. 1. Effect of initial phosphate on fermentation dynamics. Experiments were conducted in $250 \mathrm{ml}$ ( $50 \mathrm{ml}$ liquid volume) shake flasks containing low (A) or higher (B) initial levels of $\mathrm{KH}_{2} \mathrm{PO}_{4}$

(A)

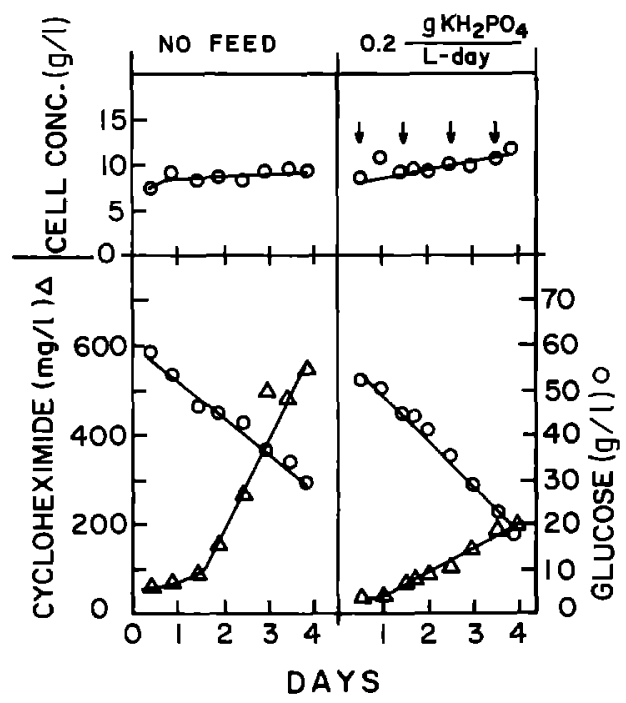

Fig. 2. Effect of multiple phosphate additions on fermentation dynamics. In the control (A) no phosphate additions were made. As indicated by the arrows, daily phosphate additions were made at a rate of $0.2 \mathrm{~g} \mathrm{KH}_{2} \mathrm{PO}_{4} / 1$-day to the experiment (B) culture 


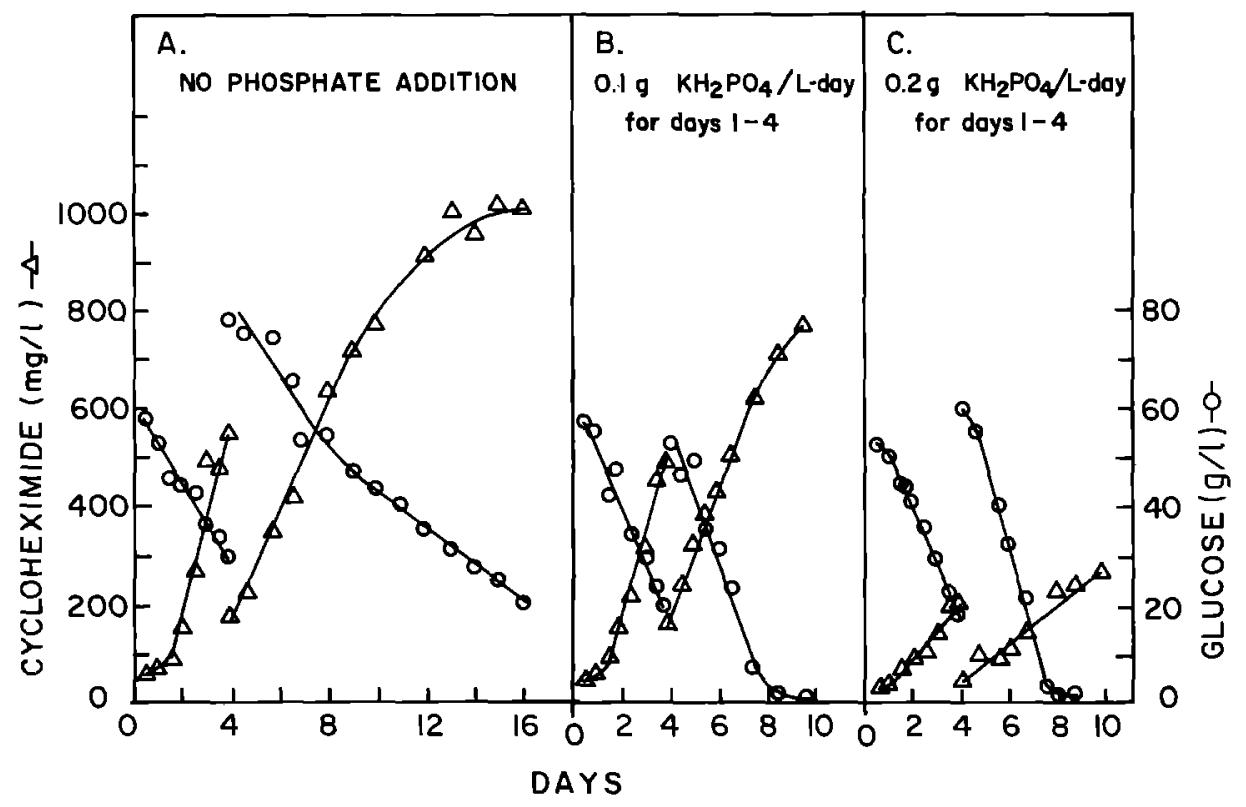

Fig. 3. Effect of phosphate additions on long term metabolic activity. Cells were initially cultured in a 31 (liquid volume) fermentor, and on the fourth day a neutral resin (XAD-4) was used to adsorb cycloheximide. The resin was then removed, and $50 \mathrm{ml}$ of broth was transferred to sterile shake flasks containing glucose. During the first 4 days, daily phosphate additions were made to the culture at a rate of $0(\mathrm{~A}), 0.10(\mathrm{~B})$, and 0.20 (C) $\mathrm{g} \mathrm{KH}_{2} \mathrm{PO}_{4} / \mathrm{l}$-day

addition can be used to control growth during the idiophase. However, this concept was not tested over a wide range of phosphate feeding rates because of the adverse effects of large phosphate additions on cycloheximide production. The observation that phosphate additions can disrupt cycloheximide production is similar to those made for cultures producing candicidin (Liu et al. 1975; Martin and Demain 1976) and streptomycin (Miller and Walker 1970).

The previous results show that in short term studies, phosphate feeding stimulated growth and sugar consumption, while feeding rates of $0.2 \mathrm{~g}$ $\mathrm{KH}_{2} \mathrm{PO}_{4} / 1$-day, reduced cycloheximide productivities. However, intermediate feeding rates ( $<0.1 \mathrm{~g} \mathrm{KH}_{2} \mathrm{PO}_{4} / 1$-day) did not adversely affect cycloheximide production (data not shown), and further studies were conducted to examine the potential of using phosphate feeding to maintain high metabolic activities and productivities for extended periods. Because the cycloheximide fermentation is sensitive to feedback regulation, it is necessary to remove cycloheximide from the broth to permit synthesis for extended periods. To conduct these studies, cells were cultured for 4 days in a 3-liter fermentor with phosphate feeding rates of $0,0.1$, or $0.2 \mathrm{~g} \mathrm{KH}_{2} \mathrm{PO}_{4} / 1$-day. On the fourth day, the broth from these fermentors was harvested, centrifuged and cycloheximide was adsorbed from the supernatant. The supernatant and cell fractions were then combined and a portion of this broth was transferred to a sterile flask containing glucose (this procedure is further described in "Materials and methods"). After adsorbing the antibiotic and adding glucose, cultivation was continued, and no further phosphate additions were made to any of the cultures. Figure 3 and Table 2 show that over an extended period glucose consumption and cycloheximide production were reduced in the control (Fig. 3A) while cells which were fed $0.1 \mathrm{~g} \mathrm{KH}_{2} \mathrm{PO}_{4} /$ l-day for 4 days remained considerably more active based on glucose consumption, and maintained a high cycloheximide production rate (Fig. 3B). The cells which were fed $0.2 \mathrm{~g} \mathrm{KH}_{2} \mathrm{PO}_{4} / 1$-day for the initial 4 days were observed to rapidly utilize glucose, however, cycloheximide production was greatly reduced (Fig. 3C). These results demonstrate the

Table 2. Effect of phosphate feeding on long term metabolic activity and cycloheximide production. Results calculated from data in Fig. 3

\begin{tabular}{lll}
\hline $\begin{array}{l}\text { Phosphate feed } \\
\text { rate } \\
\left(\mathrm{g} \mathrm{KH} \mathrm{K}_{2} \mathrm{PO}_{4} / \text {-day) }\right.\end{array}$ & $\begin{array}{l}\text { Glucose uptake } \\
\text { rate } \\
(\mathrm{g} / 1 \text {-day) }\end{array}$ & $\begin{array}{l}\text { Cycloheximide } \\
\text { production rate } \\
\text { (mg/l-day) }\end{array}$ \\
\hline 0 & 6.7 & 107 \\
0.10 & 12.4 & 134 \\
0.20 & 16.4 & 43 \\
\hline
\end{tabular}


potential for using an intermediate phosphate feed rate to permit limited cell growth and maintain high metabolic activities for extended periods without disrupting cycloheximide production. Thus, it may be possible to use such feeding schemes to extend the production phase and increase overall productivities.

\section{References}

Abou-Zeid AA (1972) Production of cycloheximide by Streptomyces. Acta Microbiol Pol Ser (B) 4:83-88

Doskocil J, Hostalek Z, Kasparova J, Zajicek J, Herold M (1959) Development of Streptomyces aureofaciens in submerged culture. J Biochem Microbiol Technol Eng $1: 261-271$

Kominek LA (1975a) Cycloheximide production by Streptomyces griseus: control mechanisms of cycloheximide biosynthesis. Antimicrob Agents Chemother 7:856-860

Kominek LA (1975b) Cycloheximide production by Streptomyces griseus: alleviation of end-product inhibition by dialysis-extraction fermentation. Antimicrob Agents Chemother 7:861-863

Lilley G, Clark AE, Lawrence GC (1981) Control of the production of cephamycin $\mathrm{C}$ and thienamycin by Streptomyces cattleya NRRL 8057. J Chem Tech Biotechnol 31:127-134

Liras P, Villanueva JR, Martin JF (1977) Sequential expression of macromolecule biosynthesis and candicidin formation in Streptomyces griseus. J Gen Microbiol 102:269-277

Liu C-M, McDaniel LE, Schaffner CP (1975) Factors affecting the production of candicidin. Antimicrob Agents Chemother 7:196-202

Martin JF, Demain AL (1976) Control by phosphate of candicidin production. Biochem Biophys Res Comm $71: 1103-1109$
Martin JF (1977) Control of antibiotic synthesis by phosphate. Adv Biochem Eng 6:105-127

Martin JF, Demain AL (1980) Control of antibiotic biosynthesis. Microbiol Rev 44:230-251

Mertz FP, Doolin LE (1973) The effect of inorganic phosphate on the biosynthetis of vancomycin. Can $\mathrm{J}$ Microbiol $19: 263-270$

Miller AL, Walker JB (1970) Accumulation of streptomycinphosphate in cultures of streptomycin producers grown on a high phosphate medium. J Bacteriol 104:8-12

Payne GF (1984) Enhanced secondary metabolite production through on-line product removal. Ph.D. thesis, The University of Michigan

Pirt SJ, Righelato RC (1967) Effect of growth rate on the synthesis of penicillin by Penicillium chrysogenum in batch and chemostat cultures. Appl Microbiol 15:1284-1290

Rao KK, Gupta AR (1975) Inhibition of tryptophan synthetase by phosphate in alkaloid producing culture of Aspergillus fumigatas. Naturwissenschaften 62:394-395

Shirato S, Nagatsu C (1965) Fermentation studies with Streptomyces griseus. I Carbohydrate sources for the production of protease and streptomycin. Appl Microbiol 13:669-672

Somogyi M (1952) Notes on sugar determination. J Biol Chem 195: $19-23$

Takeshita M, Takahashi H, Okuda T (1962) Studies on Streptomyces antibiotic, cycloheximide. XIII New spectrophotometric determination of cylcoheximide. Chem Pharm Bull 10:304-308

Wang HY, Kominek LA, Jost JL (1981) On-line extraction fermentation processes. In: Moo-Young $M$ (ed) Advances in biotechnology, pp 601-607

Weinberg D (1978) Secondary metabolism: regulation by phosphate and trace elements. Folia Microbiol 23:496-504

Received May 29, 1987/Accepted September 21, 1987 